\title{
STEADY STATE OPERATING POINTS OF THE DOUBLY FED CASCADED INDUCTION MACHINE
}

\author{
Fellipe. L. Neves ${ }^{1}$, Carlos H. S. de Vasconcelos ${ }^{2}$, Danilo. B. Lima ${ }^{3}$, \\ Antonio C. Ferreira ${ }^{1}$ and Richard. M. Stephan ${ }^{1}$. \\ COPPE/UFRJ, Rio de Janeiro, Brazil ${ }^{1}$, CEFET-MG, Campus III, Leopoldina, Brazil ${ }^{2}$, University of Oldenburg, Germany ${ }^{3}$ \\ fellipelessa@gmail.com, vasconcelos@leopoldina.cefetmg.br, daniloblima@gmail.com, \\ ferreira@coep.ufrj.br, richard@dee.ufrj.br
}

\begin{abstract}
Doubly Fed Induction Machines (DFIM) have many industrial applications and are also used as Wind Power generators. The brushes, necessary to supply energy to the rotor, are the main drawback of these machines. Therefore there are interest on Brushless Doubly Fed Induction Machines (BDFIM). The Doubly Fed Cascaded Induction Machine (DFCIM) can be used as a starting point in the study of the BDFIM. Moreover, the DFCIM can also find itself useful applications due to its simpler construction, compared to BDFIM. The present paper will expose the theory of steady state operation of the DFCIM. Operating points, power flow, simulations and experimental results will be presented.
\end{abstract}

Keywords - Induction Machine, Doubly Fed Induction Machine, Wound Rotor Induction Machine, Brushless Doubly Fed Induction Machine.

\section{NOMENCLATURE}

$\begin{array}{cl}\text { Subscripts } & \\ 1 & \text { Main machine } \\ 2 & \text { Control machine } \\ r & \text { Rotor } \\ s & \text { Stator }\end{array}$

$\begin{array}{ll}\text { Variables } & \\ a & \text { Effective turn ration between stator and rotor } \\ R & \text { Resistance } \\ L_{l} & \text { Leakage inductance } \\ L & \text { Inductance } \\ M & \text { Mutual inductance } \\ Z & \text { Impedance } \\ f & \text { Frequency } \\ p, q & \text { Number of pole pairs } \\ \omega & \text { Angular velocity } \\ s & \text { Slip } \\ V & \text { Voltage } \\ I & \text { Current } \\ P & \text { Power machine }\end{array}$

\section{INTRODUCTION}

The large use of Squirrel Cage Induction Motors (SCIM) in residential, commercial and industrial applications reflects their robust and reliable operation. With the advent of power electronics converters, the restrictions in speed control of

Manuscript received 16/12/2011; first review on 23/02/2012; second review on 29/02/2012. Accepted for publication 29/02/2012 by recommendation of the Editor João Onofre Pereira Pinto.
SCIM have been overcome. Moreover, the availability of cheap electronic processors and the establishment of vector control methods gave to the SCIM's the premium dynamic performance of DC drives [1].

For reduced speed control range, the Wound Rotor Induction Machine (WRIM) finds an application niche by supplying the rotor windings with an electronic converter of lower rating. The smaller the speed range, the cheaper the electronic converter. The WRIM is then called Doubly Fed Induction Machine (DFIM). The performance improvement in comparison with the traditional WRIM's, that have passive circuits connected to the rotor windings, justifies the new acronym [2].

However, the brushes, necessarily present in DFIM, still represent a source of mechanical and electrical failures. Since the beginning of the 20th century, many studies have been carried out in order to develop a machine that could surpass this disadvantage. These studies lead to the development of the brushless doubly fed induction machine, or BDFIM. The first attempts of creating such machine can be traced down to the machines proposed by Siemens and Lydall [3] and Hunt [4], where wound rotor machines were used. But in 1970, Broadway and Burbridge proposed a new squirrel cage rotor for the BDFIM, the nested loop rotor [5]. Due to the special stator and rotor construction of BDFIM's, these machines raise the academic interest but few are the industrial applications.

The connection of two WRIM, both mechanically and electrically, can have a higher commercial appeal since WRIM's are of standard manufacturing. This configuration is called Doubly Fed Cascaded Induction Machine (DFCIM) and is depicted in Figure 1. Furthermore, once the shafts are mechanically coupled, the rotation speed is the same, eliminating the need of brushes (BDFCIM - Brushless Doubly Fed Cascaded Induction Machine) [6]. The main use of this machine seems to be as generator in wind power plants [7] [8] [9].

The present paper aims the establishment of the static characteristics of DFCIM as a contribution to the dissemination of this machine.

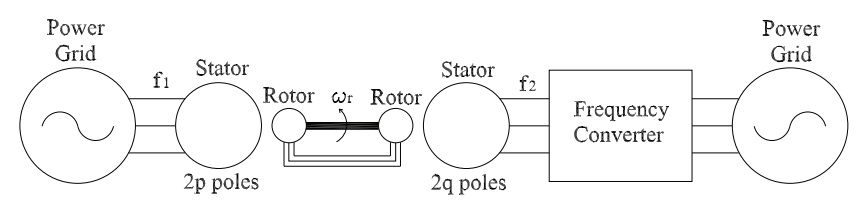

Fig. 1. Doubly Fed Cascaded Induction Machine (DFCIM). 


\section{OPERATING POINTS}

To start the reasoning, the three known operating modes of induction machines (motor, generator and plugging) are illustrated in Figure 2 [10] [11]. As the DFCIM consists of two interconnected wound rotor induction machines, a total of nine $(3 \times 3)$ operating points can be expected.

As plugging exists with the inversion of the supply phase sequence, this condition do not need to be considered for the machine directly connected to the grid. Therefore, from the nine mentioned operating points, just six $(3 \times 2)$ need to be taken into account and are indicated in Figure 3 as $A_{i j}$, with $i=1,2,3$ and $j=1,2$. Observing the rotating magnetic flux directions (indicated by rounded arrows in the figures) of stator and rotor and for the sake of symmetry and completeness, a fourth row must be added to complete all possibilities, as shown in Figure 3. Interestingly, the value of $w_{2 r}$ in the fourth line is the exact opposite of the value of the third line and so, in fact, nothing new is added with this new line. The stable operating points can be determined based on the conditions that must be fulfilled to interconnect the rotor windings in steady state, which are [12] [13]:

- Equal phase sequence;

- Equal rotor angular electrical frequencies $\left(\omega_{1 r}=\omega_{2 r}\right)$;

- Equal mechanical rotor speed $\left(\omega_{r}\right)$.

The synchronous speeds of the machines presented in Figure 1 are:

$$
\omega_{1}=\frac{2 \pi f_{1}}{p} ; \quad \omega_{2}=\frac{2 \pi f_{2}}{q}
$$

For the same mechanical rotational speed $\left(\omega_{r}\right)$, the angular frequencies of currents and voltages on the two rotor windings are:

$$
\begin{aligned}
& \omega_{1 r}=2 \pi f_{1}-p \omega_{r} \\
& \omega_{2 r}=2 \pi f_{2}-q \omega_{r}
\end{aligned}
$$

The direction of rotation of the established magnetic flux depends on the phase sequence and this is indicated by the rounded arrows in Figure 2 and Figure 3.

Considering the two wound rotor machines constructed on the same principles, just differing on the power rating and pole number, the two machines, when operating as motor or generator, must be supplied with inverted phase sequences to allow the connection suggested in Figure 1 (i.e., one machine in front of the other) [14]. When one of the machines is in the plugging operating mode, the phase sequences are the same. This fact can be observed in Figure 3 by the arrows indicating the stator flux rotation.

The induced rotor voltages have the same phase sequence of the stator when the machine is in motor or plugging mode, but presents an inverted phase sequence when in generator mode. This can be seen in both Figure 2 and Figure 3 by the arrows indicating the rotor flux rotation [15].

Always, when the rotors have inverted phase sequences, a transposition of the rotor connections is necessary, as indicated in Figure 3.
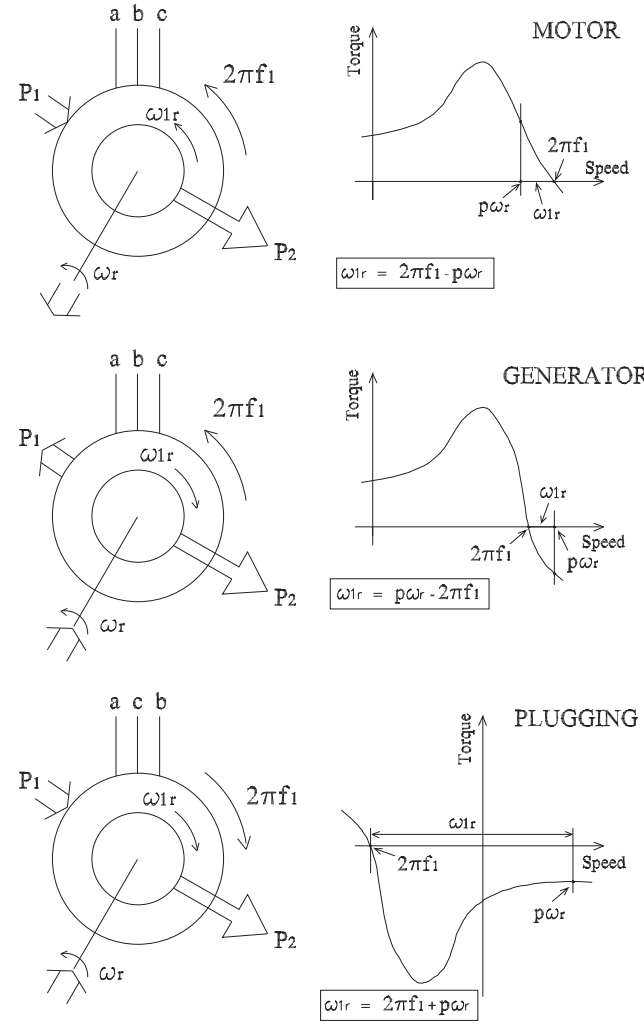

Fig. 2. Operation points of an induction machine

The operating conditions will be exemplified with the case of the element $A_{11}$ of the 4 x 2 matrix in Figure 3. Imposing $\omega_{1 r}=\omega_{2 r}$, it follows:

$$
2 \pi f_{1}-p \omega_{r}=2 \pi f_{2}-q \omega_{r}
$$

Then:

$$
\omega_{r}=\frac{2 \pi\left(f_{1}-f_{2}\right)}{(p-q)}
$$

Similar reasoning can be easily established for all operating points, completing the matrix. Considering $f_{1}$ the main supply frequency and $f_{2}$ the control frequency, the third and fourth column of this table has no practical interest since it makes no sense to change the phase sequence of the main supply. The columns can be divided into two connection sets:

- The rotor connections are not transposed and when $f_{2}=0$, the rotor speed is given by $\omega_{r}=2 \pi f_{1} /(p+q)$.

- The rotor connections are transposed and when $f_{2}=0$, the rotor speed is given by $\omega_{r}=2 \pi f_{1} /(p-q)$.

A comparison with the synchronous speed of the main machine $\left(2 \pi f_{1} / p\right)$, highlighting the control possibilities of the rotor speed $\left(\omega_{r}\right)$ as function of the frequency $f_{2}$ and the supply phase sequence, is summarized in Figure 4.

It is interesting to point out that in all operating points, independently of the speed, the DFCIM can act as motor or generator, exactly as a synchronous machine does, in spite of the fact that the basic ingredients of the DFCIM are induction machines. The conditions of Motor, Generator or Plugging, 
used to establish the Figure 3, are now left behind and play no significant role. The relative speeds of stator flux, rotor flux and rotor mechanical shaft are the deterministic factors.

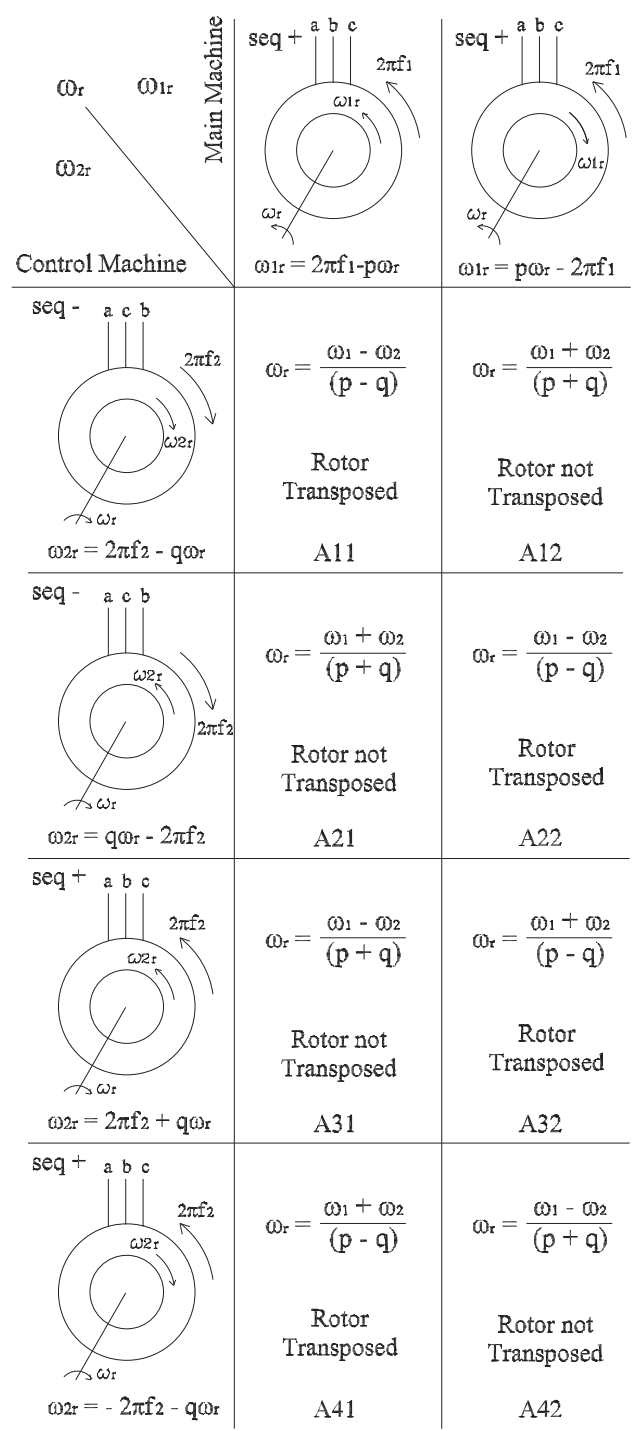

Fig. 3. Operating points of the DFCIM.

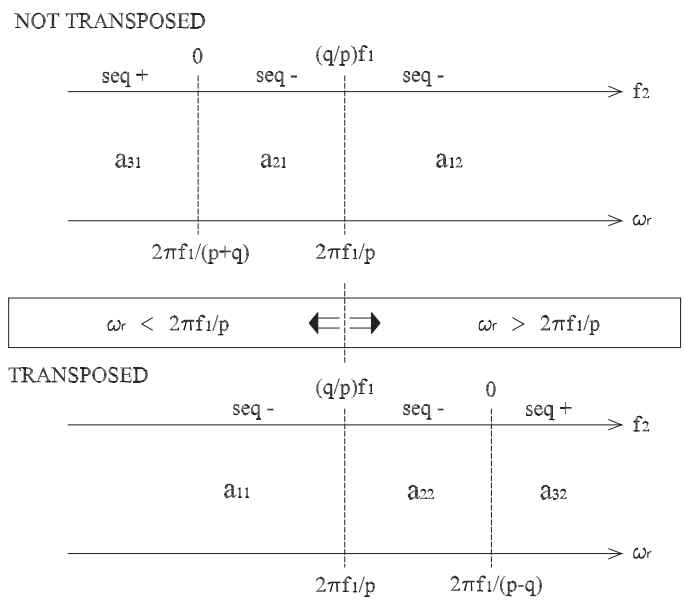

Fig. 4. Speed control possibilities for a DFCIM. $a_{i j}$ refers to row $i$, column $j$ in the matrix $4 \times 2$ of Figure 3

\section{STEADY STATE EQUIVALENT CIRCUIT}

In order to be able to analyze the DFCIM the following hypothesis will be assumed:

- Ideal distribution of stator and rotor windings, i.e., space harmonics are neglected;

- Iron losses and saturation are neglected;

- Only the synchronous mode of operation will be considered.

With the assumptions made above, the DFCIM can be represented by the equivalent circuit in Figure 5, where $s$ is the slip of machine, $\omega_{s}$ is the angular frequency of the rotor induced currents in both machines, $a$ is the effective turn ratio between stator and rotor, $R$ is the resistance, $L_{l}$ is the leakage inductance and $M$ is the mutual inductance. Subindexes 1, 2, $s$ and $r$ refer for machine 1 and 2, stator and rotor, respectively. Parameters of both machines $\left(\omega_{s}=\omega_{1 r}=\omega_{2 r}\right)$ were obtained by conventional induction machine tests and thus are all referred to stator's own side [16] [17].

From the circuit in Figure 5, according to Kirchhoff's laws, the following equations can be written:

$$
\begin{gathered}
s_{1} \frac{\bar{V}_{1}}{a_{1}^{2}}=\left[s_{1} \frac{R_{s 1}}{a_{1}^{2}}+j \omega_{s} \frac{\left(L_{l s 1}+M_{1}\right)}{a_{1}^{2}}\right] a_{1} \bar{I}_{1}+j \omega_{s} \frac{M_{1}}{a_{1}^{2}} \bar{I}_{r} \\
s_{2} \frac{\bar{V}_{2}}{a_{2}^{2}}=\left[s_{2} \frac{R_{s 2}}{a_{2}^{2}}+j \omega_{s} \frac{\left(L_{l s 2}+M_{2}\right)}{a_{2}^{2}}\right] a_{2} \bar{I}_{2}+j \omega_{s} \frac{M_{2}}{a_{2}^{2}} \bar{I}_{r} \\
0=\left[\frac{R_{r 1}}{a_{1}^{2}}+\frac{R_{r 2}}{a_{2}^{2}}+j \omega_{s}\left(\frac{\left(L_{l r 1}+M_{1}\right)}{a_{1}^{2}}+\frac{\left(L_{l r 2}+M_{2}\right)}{a_{2}^{2}}\right)\right] \bar{I}_{r} \\
+j \omega_{s}\left(\frac{M_{1}}{a_{1}} \bar{I}_{s 1}-\frac{M_{2}}{a_{2}} \bar{I}_{s 2}\right)
\end{gathered}
$$

Solving (5)-(7) for the rotor winding currents and substituting back in (5) and (6) leads to:

$$
s_{1} \bar{V}_{s 1}=\left(Z_{s 1}+Z_{r 1}\right) \bar{I}_{s 1}-Z_{r 12} \bar{I}_{s 2}
$$

$$
s_{2} \bar{V}_{s 2}=\left(Z_{s 2}+Z_{r 2}\right) \bar{I}_{s 2}-Z_{r 12} \bar{I}_{s 1}
$$

Where:

$$
\begin{aligned}
Z_{s 1} & =s_{1} R_{s 1}+j \omega_{s} L_{s 1} \\
Z_{s 2} & =s_{2} R_{s 2}+j \omega_{s} L_{s 2} \\
Z_{r 1} & =\frac{\omega_{s}^{2} M_{1}^{2}}{\left(\frac{R_{r 1}}{a_{1}^{2}}+\frac{R_{r 2}}{a_{2}^{2}}\right)+j \omega_{s}\left(L_{r 1}+L_{r 2}\right)} \\
Z_{r 2} & =\frac{\omega_{s}^{2} M_{2}^{2}}{\left(\frac{R_{r 1}}{a_{1}^{2}}+\frac{R_{r 2}}{a_{2}^{2}}\right)+j \omega_{s}\left(L_{r 1}+L_{r 2}\right)} \\
Z_{r 12} & =\frac{\omega_{s}^{2} M_{1} M_{2}}{\left(\frac{R_{r 1}}{a_{1}^{2}}+\frac{R_{r 2}}{a_{2}^{2}}\right)+j \omega_{s}\left(L_{r 1}+L_{r 2}\right)}
\end{aligned}
$$




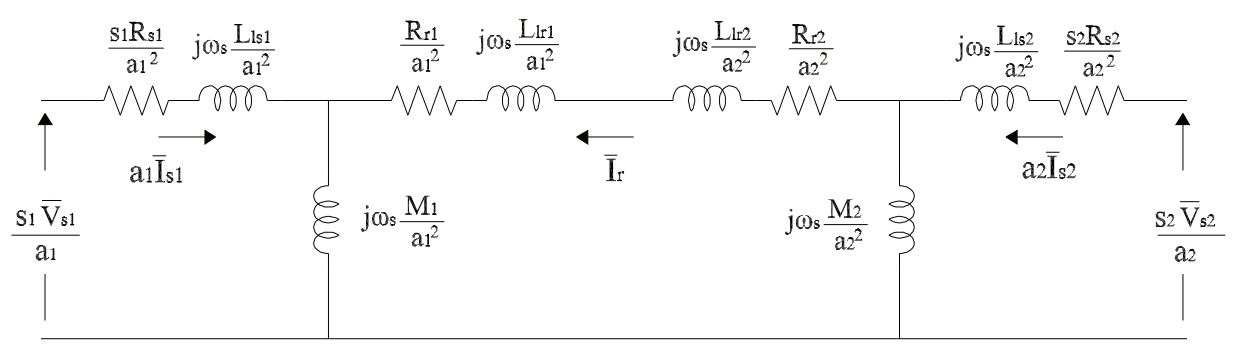

Fig. 5. DFCIM circuit referred to rotor frequency.

An equivalent circuit may be proposed based in (8) and (9) as shows Figure 6. Isolating both stator currents leads to:

$$
\begin{aligned}
& \bar{I}_{s 1}=\frac{\left(Z_{s 2}+Z_{r 2}\right) s_{1} \bar{V}_{s 1}+Z_{r 12} s_{2} \bar{V}_{s 2}}{\left(Z_{s 1}+Z_{r 1}\right)\left(Z_{s 2}+Z_{r 2}\right)-Z_{r 12}^{2}} \\
& \bar{I}_{s 2}=\frac{\left(Z_{s 1}+Z_{r 1}\right) s_{2} \bar{V}_{s 2}+Z_{r 12} s_{1} \bar{V}_{s 1}}{\left(Z_{s 1}+Z_{r 1}\right)\left(Z_{s 2}+Z_{r 2}\right)-Z_{r 12}^{2}}
\end{aligned}
$$

As machine 1 is connected to the power grid, the voltage phasor $V_{1}$ will be the angular reference and therefore will be made purely real. In the meantime the voltage phasor $V_{2}$ will be supposed to have a phase angle $\theta_{v}$. This way $\bar{V}_{1}=V_{1}$, and $\bar{V}_{2}=V_{2} e^{j \theta}$. Even though both voltages have different frequency, when referred to rotor side, they have the same frequency and thus the phase angle can have a meaning.

The input power in both machines could be calculated by:

$$
P_{s}=\operatorname{Re}\left\{3 \bar{V}_{s} \bar{I}_{s}^{*}\right\}
$$

The total mechanical torque in DFCIM's shaft produced by both machines is calculated from (14), where, $p$ and $q$ are the pole-pair number of machines 1 and 2 , respectively; $\omega_{1}$ is the supply voltage angular frequency of machine $1\left(\omega_{1}=2 \pi f_{1}\right)$ and $P_{g}$ is the power transferred across the air gap from stator to rotor. The negative sign comes from the fact that machines are mechanically coupled facing each other.

$$
T=\frac{p}{\omega_{1}} P_{g 1}-\frac{q}{\omega_{2}} P_{g 2}
$$

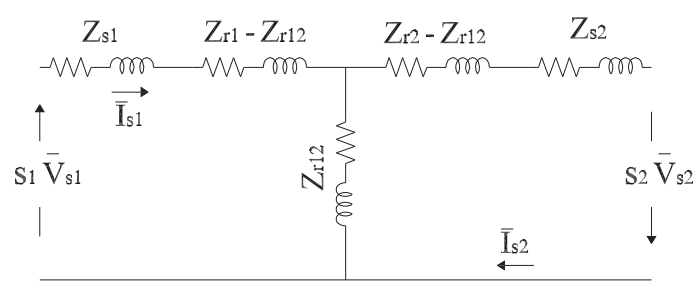

Fig. 6. DFCIM equivalent circuit.

In this case, with the hypothesis made before, $\mathrm{Pg}$ will be equal to the input power less stator ohmic losses. This paper will use the load convention, i.e., positive values of power means that powers go into the machine.

\section{POWER FLOW IN DFCIM}

In order to bring out the essential points of power flow in the DFCIM the steady state performance of an idealized machine will be analyzed [18] [19], where in addition to the assumptions made in Section III, the following assumptions are made:

- The machine is loss-free, the stator and rotor resistances are neglected;

- Stator and rotor windings of each machine with the same number of turns (i.e. $a=1$ );

- The rotors electrical connections are not transposed;

A similar analysis has been presented by Smith [12] but was limited to the connection of two similar machines.

With the simplifications assumed above, the DFCIM can be represented by the equivalent circuit in Figure 7.

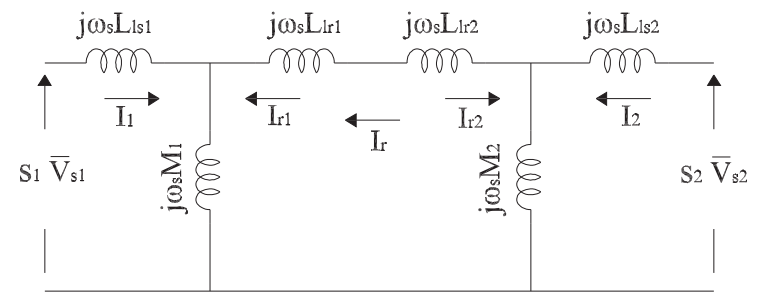

Fig. 7. Simplified DFCIM equivalent circuit at rotor frequency.

As both machines are generally supplied at different frequencies, the phase difference between these voltages can only have any meaning recalling that the DFCIM is operating in a synchronous mode with the two stator inducing rotor currents of same frequency. As such the concept of load angle applies as in all synchronous machines as discussed by Smith [12] [20] and Williamson [14]. From Figure 7, a system of equations that balance the voltage drops can be written as:

$$
\begin{gathered}
s_{1} \bar{V}_{s 1}=\left[j \omega_{r}\left(L_{l s 1}+M_{1}\right)\right] \bar{I}_{1}+j \omega_{r} M_{1} \bar{I}_{r} \\
s_{2} \bar{V}_{s 2}=\left[j \omega_{r}\left(L_{l s 2}+M_{2}\right)\right] \bar{I}_{2}+j \omega_{r} M_{2} \bar{I}_{r} \\
0=\left[j \omega_{r}\left(\left(L_{l s 1}+M_{1}\right)+\left(L_{l s 2}+M_{2}\right)\right)\right] \bar{I}_{r}+j \omega_{r} M_{1} \bar{I}_{1}-j \omega_{r} M_{2} \bar{I}_{2}
\end{gathered}
$$

Solving the (15)-(17) for the stator winding currents:

$$
\begin{aligned}
& \bar{I}_{1}=\frac{-s_{1} V_{1}}{\omega_{s}\left(\frac{L_{1} L_{2}-M^{2}}{L_{2}}\right)} e^{\frac{-j \pi}{2}}-\frac{s_{2} V_{2}}{\omega_{s}\left(\frac{L_{1} L_{2}-M^{2}}{M}\right)} e^{j\left(\theta_{v}-\frac{\pi}{2}\right)} \\
& \bar{I}_{2}=\frac{-s_{1} V_{1}}{\omega_{s}\left(\frac{L_{1} L_{2}-M^{2}}{M}\right)} e^{\frac{-j \pi}{2}}+\frac{s_{2} V_{2}}{\omega_{s}\left(\frac{L_{1} L_{2}-M^{2}}{L_{1}}\right)} e^{j\left(\theta_{v}-\frac{\pi}{2}\right)}
\end{aligned}
$$


Where:

\section{EXPERIMENTAL WORKBENCH}

$$
\begin{aligned}
L_{1} & =L_{s 1}-\frac{M_{1}^{2}}{L_{r 1}+L_{r 2}} \\
L_{2} & =L_{s 2}-\frac{M_{2}^{2}}{L_{r 1}+L_{r 2}} \\
M & =\frac{M_{1} M_{2}}{L_{r 1}+L_{r 2}}
\end{aligned}
$$

Being the input power defined by (13) and considering (18) and (19), it follows:

$$
\begin{gathered}
P_{1}=-3 \frac{s_{2} V_{s 1} V_{s 2}}{\omega_{s}\left(\frac{L_{1} L_{2}-M^{2}}{M}\right)} \sin \left(\theta_{v}\right) \\
P_{2}=3 \frac{s_{1} V_{s 1} V_{s 2}}{\omega_{s}\left(\frac{L_{1} L_{2}-M^{2}}{M}\right)} \sin \left(\theta_{v}\right)
\end{gathered}
$$

Remembering that the synchronous operation of the cascaded connection requires that $s_{1} \omega_{1}=s_{2} \omega_{2}$, (21) and (22) may be expressed on a per-unit frequency basis as:

$$
\frac{P_{1}}{\omega_{1}}=-\frac{P_{2}}{\omega_{2}}=\frac{-3 V_{s 1} V_{s 2}}{\omega_{1} \omega_{2}\left(L_{1} L_{2}-M\right)} \sin \left(\theta_{v}\right)
$$

Calling "natural synchronous speed" $\omega_{n}$ the speed that the DFCIM would run when machine 2 is fed with DC current, $\omega_{n}=\omega_{1} /(p+q)$, the following conclusions may be drawn regarding the balance between the input power in both machines:

- the division of power between the machines is related to the frequency at which they are excited; although the relationship presented in (23) will be modified in a real machine, due to the losses, the general concept that the machine that is supplied at higher frequency carries more power still holds;

- power flows in opposite directions in each machine when operating below $\omega_{n}$ and in the same directions when operation above $\omega_{n}$, no matter if the connection is operating as a motor or a generator; this is further illustrated in Figure 8. The same considerations are valid for the transposed case, just observing that the "natural synchronous speed" changes to $\omega_{n}=\omega_{1} /(p-q)$.

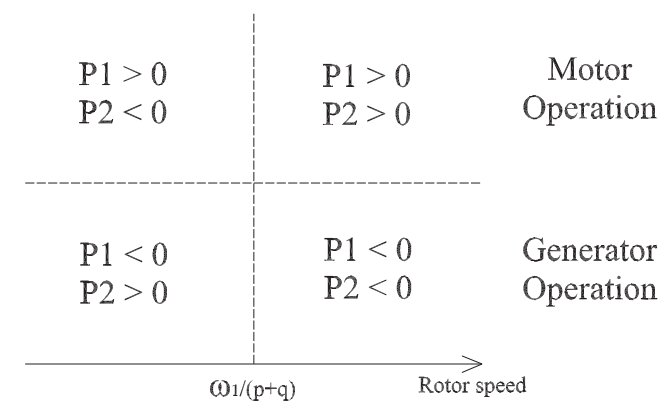

Fig. 8. Power flow in the DFCIM.
An experimental workbench, illustrated in Figure 9, has been set up to validate the theoretical results previously presented.

The parameters of both machines are given in TABLE I.

The DFCIM is coupled to a separately excited DC machine through a belt, as seen in Figure 9. It will act either as a turbine or as a load. Its behavior will be done by controlling its field excitation voltage.

TABLE I PARAMETERS OF MACHINES

\begin{tabular}{ccc}
\hline Parameters & Machine 1 & Machine 2 \\
\hline Number of Pair-Poles & 3 & 2 \\
\hline Effective Turn Ratio & 1.4 & 1.5 \\
\hline Stator Resistance $(\Omega)$ & 5.0 & 3.3 \\
\hline Rotor Resistance $(\Omega)$ & 4.5 & 4.6 \\
\hline Stator Leakage Inductance $(\mathrm{mH})$ & 9.0 & 8.0 \\
\hline Rotor Leakage Inductance $(\mathrm{mH})$ & 9.0 & 8.0 \\
\hline Magnetizing Inductance $(\mathrm{mH})$ & 98.0 & 160.0 \\
\hline Rated Voltage $(\mathrm{V})$ & 127.0 & 127.0 \\
\hline Rated Power $(\mathrm{W})$ & 370.0 & 370.0 \\
\hline Rated Torque $(\mathrm{N} . \mathrm{m})$ & 2.95 & 1.96 \\
\hline
\end{tabular}

The procedure to start the DFCIM and synchronize the two rotor rotating fields was:

1. Adjust the speed of the DC machine to reach the expected value of steady state, according to Figure 3;

2. Gradually raise stator voltages until the desired voltage is reached;

To measure the torque produced, a digital sensor was coupled to the DC machine's frame. Power flow and currents in machines' stator were measured with a Hall Effect pincer wattmeter. Instruments used in these tests are shown in Figure 10 .

By using the parameters of TABLE $I$ it is possible to predict the power flow and stator current values. In this test both machines will be supplied at $60 \mathrm{~Hz}$. Figure 11, Figure 12 and Figure 13 show both these magnitudes and the total torque as a function of $\theta$. The experimental test consists of applying different values of torque, through the DC machine, and measure the power and currents in each machine in order to compare with the previous curves.

Figure 14 show these results. In order to compare measured with theoretical results, these last ones have to be expressed as function of torque instead of phase angle. So, calculated power and currents are expressed as function of torque for values between $190^{\circ}$ and $320^{\circ}$. Figure 15 show measured values compared with theoretical results. It is possible to see that they have approximate values.

\section{CONCLUSIONS}

This paper presented the theory of the doubly fed cascaded induction machine (DFCIM). The fundamental concepts to understand its operation in steady state were shown, and, based on these considerations, the possible points of operation were deduced. Also a steady-state analysis of an idealized DFCIM was performed, describing the equations and power flow of the set. To validate this theory, simulations in 


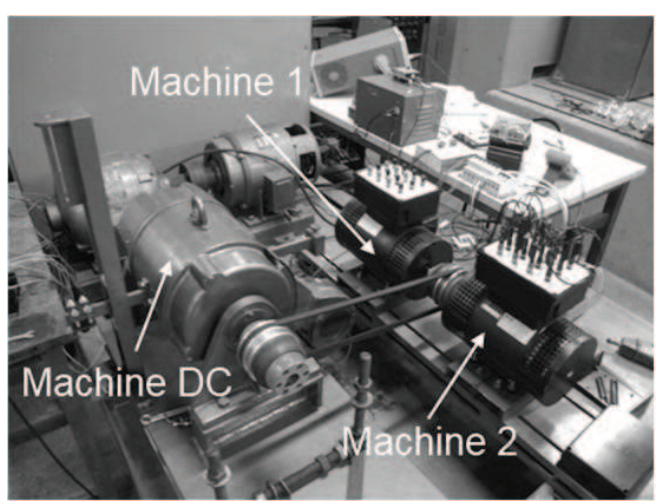

Fig. 9. Experimental Workbench for the DFCIM.

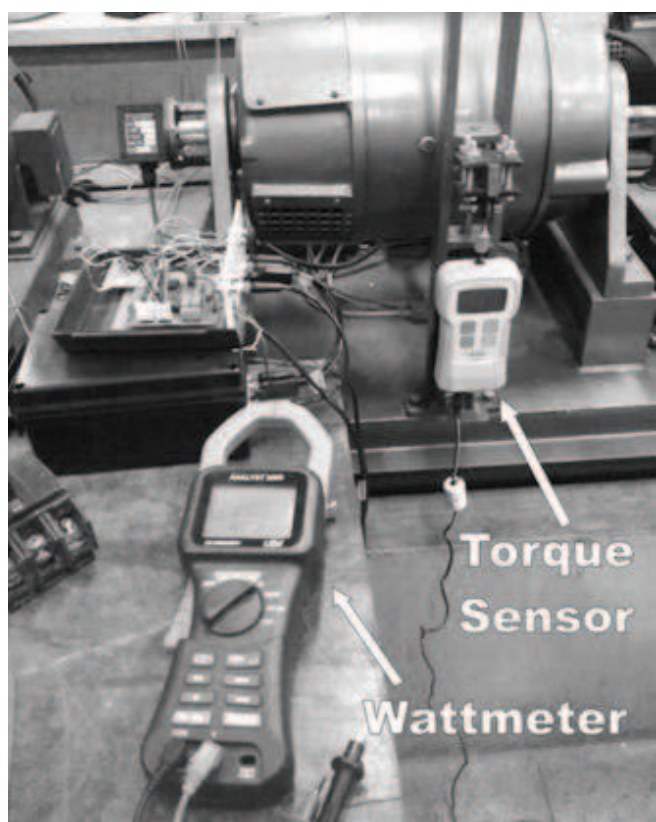

Fig. 10. Torque, Power and current sensors.

MATLAB and an experimental workbench of DFCIM were used. The results obtained were compared and confirmed the theoretical model proposed in this paper.

With the proposed model it is possible to understand the operation and behavior of the brushless cascaded doubly fed induction machine: a reliable machine with fairly simple

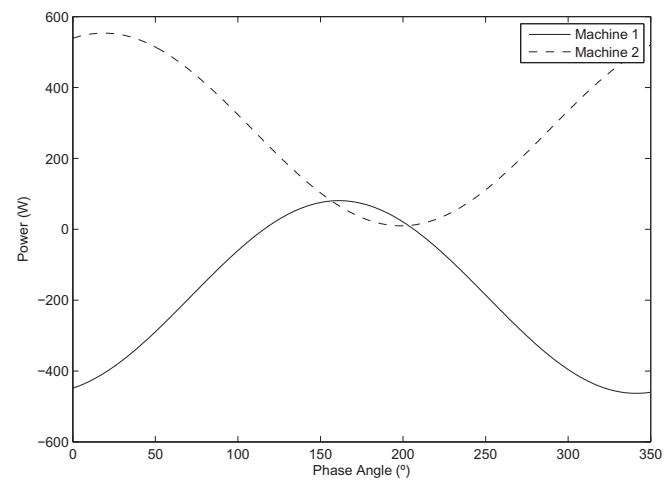

Fig. 11. Power flow in machine 1 and 2.

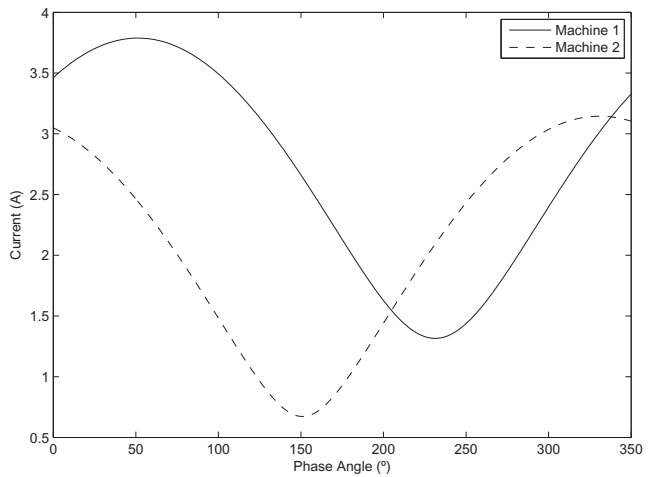

Fig. 12. Stator currents of machines 1 and 2.

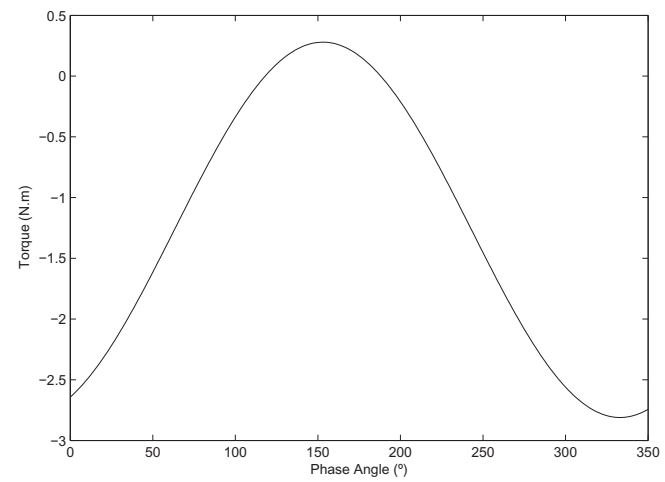

Fig. 13. Total torque of DFCIM.

construction, combining the advantages of the double fed machines and without the need of brushes and slip rings. The next step of this study is the establishment of a dynamic model.

\section{ACKNOWLEDGEMENT}

The authors thank CNPq and the technicians Sergio Ferreira, Andre Barbosa and Genésio Santana for the support in the assembly and operation of the experimental workbench.

\section{REFERENCES}

[1] W. Leonhard. Control of Eletrical Drives. Springer Verlag, 3 edition, 2001.

[2] R. G. Oliveira; J. L. Silva; S. R. Silva; B. R. Junior; W. Hofmann. Desenvolvimento de uma nova estratégia de

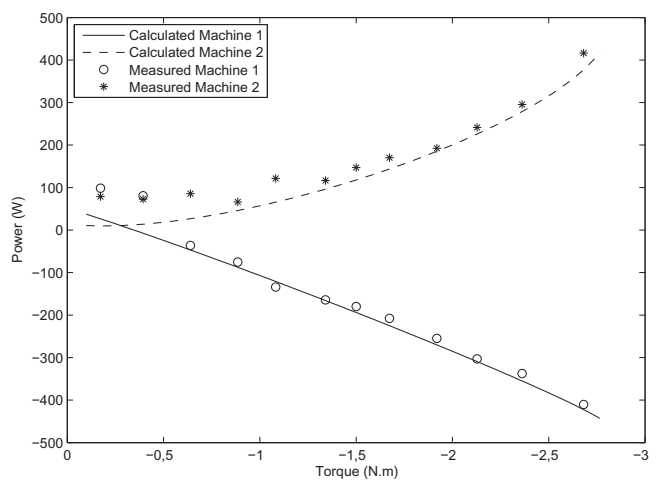

Fig. 14. Measured and calculated power flow. 


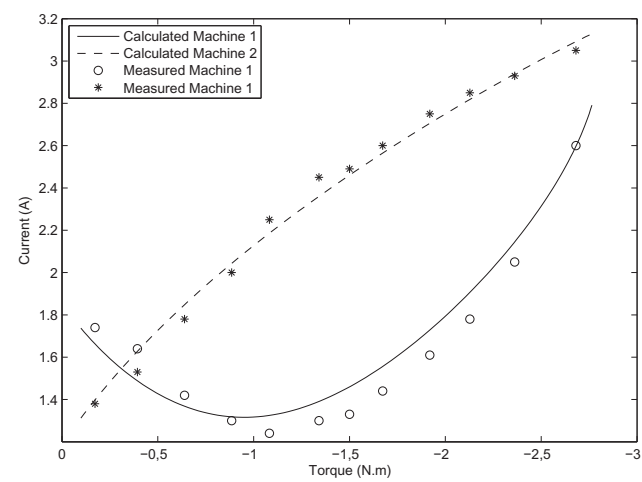

Fig. 15. Measured and calculated stator currents.

controle de potência reativa em gerador de indução de dupla alimentação para turbinas eólicas. Eletrônica de Potência-SOBRAEP, pages 277-284, november 2008.

[3] S. Brothers \& Co. Ltd.; F. Lydall. Improvements in poly phase induction motors. British Patent 16839, 1902.

[4] L. J. Hunt. A new type of induction motor. Journal Institution of Electrical Engineers, pages 648-677, 1907.

[5] P. C. Roberts. A Study of Brushless Doubly Fed Induction Machines. $\mathrm{PhD}$ thesis, Emmanuel College, Univ. of Cambridge, 2004.

[6] R. W. Broadway; L. Burbridge. Self-cascaded machine: a low-speed motor or high-frequency brushless alternator. Proceedings of the Institution of Electrical Engineers, pages 1277-1290, 1970.

[7] S. Kato; N. Hoshi; K. Oguchi. Small-scale hydropower. IEEE Industry Applications Magazine, pages 32-38, 2003.

[8] M. Adamowicz; R. Strzelecki. Cascaded doubly fed induction generator for mini and micro power plants connected to grid. 13ॅr Power Electronics and Motion Control Conference, Poznan, pages 1729-1733, september 2008.

[9] B. V. Gorti; D. Zhou; R. Spee; G. C. Alexander; A. K. Wallace. Development of a brushless doubly-fed machine for a limited-speed pump drive in a waste-water treatment plant. Conference Record of the 1994 IEEE Industry Applications Society Annual Meeting, pages 523-529, october 1994.

[10] D. B. Lima; F. Lessa; A. C. Ferreira; R. M. Stephan. Operating points of a doubly cascaded induction machine. Power Electronics Conference, COBEP'09, Brazilian, Bonito, MS, pages 124-129, october 2009.

[11] A. C. Ferreira. Brushless doubly-fed induction machine : Operating characteristics and applications. Eletrônica de Potência-SOBRAEP, pages 42-48, june 2003.

[12] B. H. Smith. Synchronous behavior of doubly-fed twin stator induction machine. IEEE Transactions on Power Apparatus and Systems., pages 1227-1236, 1967.

[13] D. Picovity; D. Levy; A. E. Mahdi; T. Coffey. The cascade induction machine: a reliable and controllable motor or generator. Electric Power Systems Research, pages 193-207, 2004.

[14] S. Williamson; A. C. Ferreira; A. K. Wallace.
Generalized theory of the brushless doubly-fed machine. part 1: Analysis. IEE Proceedings Electric Power Applications, pages 111-122, March 1997.

[15] N. Chilakapati; V. S. Ramsden; V. Ramaswamy; J. Zhu. Investigation of doubly fed twin stator induction motor as a variable speed drive. International Conference on Power Electronic Drives and Energy Systems for Industrial Growth, pages 160-165, 1998.

[16] J. N. B. Silva. Modelagem e simulação da máquina de indução de dupla alimentação em cascata sem escovas. Master's thesis, UFRJ/COPPE, 2009. RJ.

[17] D. B. Lima; F. Lessa; A. C. Ferreira; R. M. Stephan. Steady state analysis of the doubly fed cascaded induction machine. International Conference on Industry Applications (INDUSCON), São Paulo, SP, pages 1-4, november 2010.

[18] F. Lessa; D. B. Lima; A. C. Ferreira; R. M. Stephan. Comprovação experimental dos pontos de operação de uma máquina de indução em cascata de dupla alimentação. Congresso Brasileiro de Automática, Bonito, MS, 2010.

[19] H. Voltolini; R. Carlson; F. Rüncos. A study about the power flow in brushless doubly fed asynchronous generators for wind power systems. Eletrônica de Potência-SOBRAEP, pages 85-92, july 2006.

[20] H. Smith. Variable speed twin stator induction machine. Electrical Times, pages 53-54, August 1969.

\section{BIOGRAPHIES}

Fellipe Lessa Neves received the B.Sc. degree in Electrical Engineering from the Federal University of Rio de Janeiro, Rio de Janeiro, Brazil, in 2009. Since 2009, he is a M.Sc. student of Electrical Engineering in COPPE, Federal University of Rio de Janeiro. His main interests are in the fields of control of electrical drives, power electronics, renewable energy and energy generation.

Carlos Henrique Silva de Vasconcelos received the B.Sc. and M.Sc. degrees from the Pontifical Catholic University of Minas Gerais, Belo Horizonte, Brazil, in 2001 and 2006, respectively, he is a D.Sc. student of Electrical Engineering in COPPE, Federal University of Rio de Janeiro. His main interests are in the fields of control of electrical drives, power electronics, renewable energy and energy generation.

Danilo de Brito Lima received the B.Sc. degree in Electrical Engineering from the Federal University of Rio de Janeiro, Rio de Janeiro Brazil, in 2010. Since 2010 he is a M.Sc. student of Renewable Energies in University of Oldenburg, Oldenburg, Germany. His main interests are the use of renewable energies in distributed generation systems and smart grids.

Antonio Carlos Ferreira received the B.Sc. and M.Sc. degrees from the Federal University of Rio de Janeiro, Rio de Janeiro, Brazil, in 1987 and 1991, respectively, and the $\mathrm{Ph} . \mathrm{D}$. degree from the University of Cambridge, Cambridge, U.K., in 1997, all in Electrical Engineering. Since 1989, he has been with the Graduate School of Engineering, Federal University of Rio de Janeiro, where he is currently an Associate Professor, teaching at both under-graduate and post- 
graduate levels. His main interests are power system and electrical machines.

Richard Magdalena Stephan received the B.Sc. degree in electrical engineering from the Instituto Militar de Engenharia (IME), Rio de Janeiro, in 1976, the M.Sc. degree in electrical engineering from the Federal University of Rio de Janeiro (UFRJ) in 1980, and the Dr.-Ing. degree in electrical engineering from Ruhr Universitat Bochum, Germany, in 1985. He has an MBA degree (2005) from the Center for Scientific Enterprise, London (CSEL), on the Technology Enterprise Development. During 1977, he worked as an engineer at Furnas Centrais Elétricas, Rio de Janeiro. Since 1978, he has been with the Department of Electrical Engineering, UFRJ. He spent a sabbatical leave at CEPEL, the Research Center of ELETROBRAS in 1993. His main interests are in the fields of applications of superconductivity, control of electrical drives and power electronics. 